\title{
Discurso del Presidente de la Federación Médica Colombiana Dr. RAFAEL PERALTA CAYON en las exequias del Profesor José del Carmen Acosta
}

La Federación Médica Colombiana, está angustiadamente consternada ante este injusto año 1966 con sus eternos sacrificios a las proceras, augustas e irreemplazables fiøuras de la Medicina Colombiana. Hoy le ha llegado el turno al Profesor verdadero, titular, emérito y honorario, doctor JOSE DEL CARMEN ACOSTA VILLAVECES, quien fuera en nuestra Federación su fundador distinguido, su expresidente, su presidente espiritual en todo tiempo, aun después de muerto.

El tradujo la significación del valor irrefutable de la inteligencia, de la consagración al estudio, la moral como norma de la vida, la preparación científica para el sólidio ejercicio profesional, la habilidad dentro de la experiencia, la independencia de carácter y ejecuciones en lo civil y ciudadano, la virtud en la sociedad y el hogar. Todo dentro de un yo equilibrado, sencillo, superdotado sólo para lo grande y noble, que es lastimoso no exista en tantas capacitaciones mentales que hemos conocido.

De allí las elevadas y singulares posiciones con que enalteció a las Facultades de Medicina, como Secretario ágil sin alma de amanuence decadente, Decano sin consignas demoledoras, creador de una Cátedra y Escuela Obstétricas de interminable prestigio en infinidad de promociones y generaciones Médicas. Estas recibieron sus sabias enseñanzas en aquellas magistrales conferencias y disquisiciones, que aún hacen eco en los ex-discípulos, ex-internos, ex-jefes de clínica, ex-profesores y profesores, agradecidos. En la maestría del arte tocúrgico, de las maniobras técnicas, mutantes, conducidas con serenidad, suavidad, y éxito sorprendentes. En múltiples tesis de grado, en el pasado feliz en que existían, o trabajos científicos similares, que dirigía con encomiable espíritu investigativo, hasta cristalizar una obra científica con publicaciones experimentales y académicas, que para todos constituyeron un Texto. Eran los tiempos de las autínticas dedicaciones a la docencia y asistencia hospitalaria, a cualquier hora del día o de la noche, porque imperaba la noción alta y altruista del desprendimiento en el derrotero de lo ético y humano.

Por ello fue el real Rector del Cuerpo Médico Colombiano, en las Universidades Nacional y Javeriana, en la Maternidad de la Hortúa, en la Academia Nacional de Medicina, Clínica de Marly, Sociedad Colombiana de Obstetricia y Ginecología, Federación Médica, Club Médico, Instituto de Protección Materno-Infantil que fundara, Asociación Colombiana de Hospitales, Comité Operativo de Salud hasta hace 3 semanas, y diferentes Instituciones Médicas, con amplias proyecciones a otros países donde era conocido y reconocido.

Nuestra Federación Médica recibió su acertada orientación y regencia operante por varios lustros, y ella desde hace más de quince años le otorgó la máxima condecoración de la Cruz de Esculapio. Cuando la compleja socialización de la Medicina fuera dogma y necesidad del Estado, fue quien la canalizó por rutas que man- 
tuvieron la dignidad profesional, y bien recordamos los dieciocho principios que impuso como requisitos mínimos para el bienestar de la sociedad y del múdico, en materia de Seguridad Social. Cuando en controversia que talvez aun no ha cesado, se enfrentaban algunas regiones del país, sus médicos y programaciones. En nuestra sede vibró la batalla erguida por el respeto al médico honesto, y se enfrentó a los mezquinos intereses que intentaron lesionarlo.

Talvez no haya existido otro compatriota que haya experimentado la satisfacción del mínimo de enemigos; probablemente Marco Fidel Suárez, con su proverbial modestia, jamás ensorbebecida. Prestigio igual no hemos visto y prevaleció aún en contados y efímeros segundos de adversidad. Si se intentaba inferirle un ataque y antes se hablaba con él, seguramente surgía el arrepentimiento y no se le hacía. Nadie dimitió tantas veces una dirección hospitalaria, sin que no se le hubiera aceptado la renuncia.

La mujer colombiana, especialmente en la sagrada y sin par misión de la maternidad, y advenimiento a la vida, admiró sus cualidades científicas y humanas. Una serie de descendencias de nuestra sociedad, recibieron su consejo, su benevolencia, hasta ser el precursor de nuestra Psicoprofilaxis obstétrica, lo mismo que su intervención oportuna cuando se comprometían dos vidas o una de ellas. Toda la República se desplazó a su consulta, jamás dió una muestra de extorsión ni de mercantilismo profesional, y no hizo distinciones aberrantes de clases sociales.

Amó a su esposa, hijas, nietos y familiares. Tanto como a la Patria, y tanto a ésta como a ellos. Hace pocos meses dentro de una ideología histórica y definida, suscribió la adhesión al sistema político y administrativo que debe ser la redención de Colombia.

Como Presidente de la Federación Médica, también traigo la vocería de lo que se ha designado Cuerpo Médico de Provincia, del norte, sur, oriente, occidente, centro y territorios nacionales. De quienes cuando mencionaban el nombre del Profesor Acosta, instituían los principios filosóficos del respeto, la caballerosidad, la erudición en ciencias biológicas, laboratorios, clínicas médica, quirúrgica, toco-ginecológica. Aquellos que en esta hora aciaga están confundidos y conmovidos, porque han visto desaparecer al prototipo del médico completo. Lo que fuera en Francia un Brindau o Pinard, en Alemania Doderlein, en Estados Unidos del Norte William o Eastman, en Suramérica Alberto Peralta Ramos.

La Federación Médica en grado sumo de dolor espiritual, exalta como paradigma de apostolado médico la meritoria, ética y digna vida del Profesor Acosta. Ante él, ante su eterna estatua de la Medicina Colombiana, hace emocionado llamamiento a sus federados, a Asmedas, a Sindicatos Médicos de Antioquia, Atlántico, Valle y demás asociaciones científicas o gremiales, para que realicen y consoliden la unión o unidad médica, lo que en sí intrínsecamente fué la filosofía y existencia del Profesor JOSE DEL CARIMEN ACOSTA. 